\title{
THE UROLOGICAL TREATMENT OF PARAPLEGIC PATIENTS AT HOME
}

\author{
By Professor Ruggero Ascol I \\ Paraplegic Centre, Milan, Italy
}

THE treatment and re-education of the paraplegic during hospitalisation in special units for paraplegics are of the first importance, but hardly less important are assistance and treatment at home following discharge from hospital after varying periods of hospitalisation.

I would like to give a brief outline of the principles and methods we follow at the Milan Paraplegic Centre with regard to urological treatment at home.

The hospitalisation of recent patients at our unit lasts at an average five to six months. Generally speaking, after that time the majority of paraplegics have derived maximum benefit. As far as walking is concerned-and as far as the use of the upper limbs in tetraplegics are concerned-the maximum has been done. Depending upon the seriousness of the lesion, the paraplegic can, in the majority of cases, walk with the help of braces and sticks of varying kinds. If this has not been achieved, patients have become expert at using a wheelchair and have learnt to transfer from the bed to the wheelchair and vice-versa. If they had bedsores they have, generally speaking, been suitably treated by medical or surgical means and have in most cases healed.

Let us now discuss the urological situation at the moment of discharge.

As I have said on various other occasions when speaking of vesical re-education and treatment, I distinguish three periods in recent traumatic lesions, by far the most frequently occurring conditions. The first period lasting roughly two to two and a half months during which, for the voiding of the bladder, the patient depends more or less entirely on the catheter. During the second period the patient is left without a catheter during the day for increasingly long periods. By means of a careful check on residual urine, attempts are made to stimulate and regularise micturition, and the patient is taught various methods for stimulation.

During the second period of treatment in hospital we begin, what might be called the didactic/psychological treatment, and patients are repeatedly told that it is indispensable that they should learn to urinate at regular intervals, that the interval between one micturition and another should, if possible, always be the same (this must be established by the doctor, as a result of a study of the patient: on an average the interval varies from two to five hours). Special attention must be devoted to the quantity of liquid administered in the 24 hours and to the mode of administration, in order to achieve a uniform formation of urine over the 24 hours.

We now come to the third period which is of particular interest to us today: the urological treatment of paraplegics at home.

The decision as to whether a patient should be discharged and whether he should be sent home, largely depends not only on his physical condition but also on his psychological state. Generally speaking, it is our aim to discharge patients who are self-sufficient or partially self-sufficient, but unfortunately it can happen 
that we are obliged, for varying social or family reasons, even to discharge patients who are still in need of treatment and assistance.

From a practical standpoint, dischargeable patients may be divided into the following categories:

(i) intelligent, capable and willing paraplegic patients, who, as a result of long hospitalisation at our centre have learnt all that is basic to the treatment of the paraplegic;

(ii) paraplegics who are not particularly capable and who have little desire to cooperate, but who at home can call on members of their family who are intelligent, capable and conscientious, both as regards to care of the patient and any medical treatment;

(iii) the third category includes patients who are not capable, who have no desire to cooperate, who are apathetic and passive and who in their families are provided with only the bare minimum of nursing care and are regarded by their families as a burden and nuisance.

During the last few days before discharge we instruct the patient in all the main rules and measures to be observed in order to keep the function of micturition working in the most satisfactory manner possible, and they are given a written form containing full instructions and prescriptions. The same is done with the relatives. Unfortunately, there are people in every family who are not suitable for nursing paraplegic patients. For this reason sooner or later complications often arise at home, and sooner or later this means a return to hospital.

In particular, the following is recommended to patients and their families: in the case of patients for whom it has been possible to achieve a good 'reflex bladder', they must try to urinate at regular intervals, and it should be stressed, that once it has been established after a certain interval the bladder when left to itself would spontaneously void its contents. It is necessary to anticipate this voiding by a voluntary voiding at least a quarter of an hour or 20 minutes before. In other words, if, for example, it is established that a bladder, when left to itself, voids its contents on an average every three hours, the patient must try to anticipate this voiding, and try to empty the bladder voluntarily every two and a half hours or every two hours and threequarters. Because of this we have adopted the slogan: 'Urinate by the clock'.

Unfortunately, not in every case is it possible to produce a responsive bladder and very often the patient is apathetic and completely lacking in cooperation. These patients spend most of the day in bed with the urinal between the thighs, not concerned either with themselves or with how and when urine is to be passed. Later we will mention the special situation of female patients. Others with a similarly defeatist attitude use the method of the 'prophylactic' extended by a rubber tube and fitted closely to the penis by means of an adjustable elastic strap. Others use Cunningham's clamp, but patients are warned against the danger of leaving it on too long, as this can result in the formation of pressure sores on the penis.

Unfortunately in the cases where little or no care is given at home, and in cases of patients who have difficulty in urinating and who have a large amount of infected residual urine, there is no alternative but to resort to an indwelling catheter.

Let us now mention, more particularly, the importance of the technique of catheterisation for patients at home. 
When treatment in hospital is over and the paraplegic returns home, it should be borne in mind that it is probable, or at all events possible, that he will to a greater or lesser extent need catheterisation. I mean patients who at the time of discharge still pass urine with difficulty, who present a certain amount of vesical residual urine (more than $150-200 \mathrm{cc}$.) and have an infected urine, or patients with reflux.

Many of these patients live in areas where there are no urologists, and where the knowledge of the local general practitioner or nurses is very insufficient regarding catheterisation and sterility. After experiencing a great many difficulties in these areas for some time, we have come to the conclusion that rather than catheterisation and urological manoeuvres practised by irexperienced physicians or nurses, catheterisation carried out by the patient himself or by an intelligent and conscientious relative (provided they are suitably instructed) are by far preferable. For this reason, a few days before discharge from the hospital we arrange for the patient himself or for a suitable member of his family to take a short practical course on catheterisation. We insist particularly on thorough sterilisation of the hands, of the forceps which inserts the catheter and of the gloves, meticulous sterilisation of the urethral meatus, in both men and women, thorough sterilisation of the lubricating material, etc. Under the direct guidance of the urologist or of the urological nurse, the patient, assisted by a relative, or the relative himself, is then taught the correct technique for inserting the catheter. I would add that we have prepared a cyclostyled sheet listing all the rules for correct catheterisation, for the use of nurses in general and for paraplegic patients being discharged from the hospital.

As regards self-catheterisation, I would mention that this is particularly easy in the woman if it is done with the help of a mirror, which has to be held by somebody.

We spoke earlier of the various categories of paraplegics who can be nursed and treated at home and we said that there are some who need only a minimum of care and assistance. However, even these patients need periodical checks, on an average twice a year. This check-up includes $(a)$ a urography, $(b)$ urine tests, (c) measuring of the residue in the bladder. Generally speaking, we begin to be concerned only when the residue exceeds $200 \mathrm{ml}$. Other patients need more frequent checks: these are the septic and subseptic cases, those who have had reflux or temperature, those who have on one or more occasions presented vesical calculi.

In patients with reflux we think it is not possible to do without the indwelling catheter, fitted with a collector and, of course, frequent antiseptic irrigations.

It is most important to keep in touch with patients who have returned home, and this is done by ambulatory examinations for those who live in Milan or near by, by correspondence or over the telephone. It is unbelievable how many difficulties, large or small, and how many complications in the field of neurological urology, can be put right by a telephone conversation.

In cases with a moderately septic condition with no general effects, we recommend periods of antiseptic or antibiotic treatment from time to time, orally or by injection. In the less severe cases we generally recommend five days of antiseptic treatment twice a month, in more serious conditions even four times a month. The drugs we are using most are those which in Italy go under the names of Urovalidin, Rifadin, Gentalin and Carbenicillin, associated with appropriate vitamin preparations. 